\title{
O USO DE ADVÉRBIOS TEMPORAIS EM NOTÍCIAS JORNALÍSTICAS: DESCRIÇÃO E ANÁLISE DE PROPRIEDADES MORFOSSSINTÁTICAS
}

\section{THE USE OF TEMPORAL ADVERBS IN NEWS REPORTING: DESCRIPTION AND ANALYSIS OF MORPHOSYNTACTIC PROPERTIES}

\author{
Gessilene Silveira Kanthack * \\ Viviane Purcina de Santana Maciel ** \\ Universidade Estadual de Santa Cruz, Ilhéus, BA, Brasil
}

\begin{abstract}
Resumo: Este trabalho descreve e analisa o comportamento morfossintático de advérbios temporais em notícias comuns veiculadas nos jornais A Tarde, da Bahia, e 0 Globo, do Rio de Janeiro. 0 objetivo é demonstrar não apenas que há diferencas de usos desses advérbios entre os dois jornais, especificamente no que tange ao seu posicionamento nas sentenças, mas também comprovar que esses advérbios não constituem uma classe homogênea, como é pressuposto, normalmente, nas descrições de orientação normativa. Na investigação, foram considerados os advérbios temporais não-oracionais que ocorriam nas posições inicial, medial e final das sentenças. Essas posiç̦ẽes foram também analisadas em função da forma do advérbio (simples - uma só palavra, e composta - mais de uma palavra), com o propósito de revelar a influência desse fator no posicionamento variável. Os resultados revelaram: a posição periférica inicial é a preferida do jornal $A$ Tarde, e a periférica final, do jornal 0 Globo; os advérbios em suas formas compostas foram mais recorrentes nas posiç,ões periféricas, e as formas simples, nas posições mediais. 0 trabalho teve como base pesquisas como as de Martelotta (1994), Neves (1999), Andrade (2004) e Costa Nunes (2009), que também revelam o comportamento variável de advérbios temporais.
\end{abstract}

Palavras-chave: Advérbios temporais; Posição; Morfossintaxe; Semântica; Usos.

Abstract: This study describes and analyzes the behavior of morphosyntactic temporal adverbs in ordinary news reporting run at the news A Tarde, in Bahia, and at 0 Globo, in Rio de Janeiro. It aims to demonstrate that there are differences in the use of these adverbs, mainly, in relation to their place in the sentences, as well as to prove that those adverbs do not belong to a homogenous class, as it is assumed at the normative orientation. It was taken into consideration the non-phrased temporal adverbs that occurred in the initial, medial and final positions in the sentences. These positions were also analyzed due to the form of the adverb (simple - a single word - and multiple phrases - more than one word) showing the influence of those factors in the variable positioning. The results showed that the initial peripheral position is more used at A Tarde and the final peripheral position, at 0 Globo; the adverbs in all their multiple ways were more used in the peripheral position, and the simple forms in the medial position. This investigation was based on Martelotta (1994), Neves (1999), Andrade (2004) and Costa Nunes (2009), studies that reveal the variable behavior of the temporal adverbs.

Keywords: Temporal adverbs; Position; Morphosyntactic; Semantic; Uses.

* Professora da Universidade Estadual de Santa Cruz - UESC, Ilhéus, BA, Brasil; gskanthack@ yahoo.com.br

** Mestre pela Universidade Estadual de Santa Cruz - UESC, Ilhéus, BA, Brasil; viviporcina@ hotmail.com 
Linha D'Água (Online), São Paulo, v. 27, n. 1, p. 139-152, jun. 2014

\section{Introdução}

Pesquisas de cunho funcional (cf. ILARI et al (1990), MARTELOTTA (1994), NEVES (1999), ANDRADE (2004), COSTA NUNES (2009), entre outros) têm revelado que os advérbios de língua portuguesa ostentam propriedades sintáticosemânticas bastante particulares, permitindo afirmar que as descrições apresentadas pelas gramáticas de orientação normativa são bastante limitadas. Essas, ao descreverem a categoria advérbio, normalmente, pressupõem que ela corresponde a uma classe bastante homogênea: o advérbio é definido, basicamente, como uma palavra invariável, que apresenta um domínio bastante restrito: é um modificador de verbo, adjetivo e advérbio, como ilustram, respectivamente, os exemplos em (1):

\section{(1) a. José compreendeu bem a questão. \\ b. José está muito animado. \\ c. José escreve muito bem.}

No intuito de ampliar o que as descrições tradicionais e linguísticas apresentam à classe dos advérbios, pesquisamos o comportamento morfossintático, em especial, dos advérbios temporais num corpus constituído de notícias comuns veiculadas nos jornais $A$ Tarde, da Bahia, e O Globo, do Rio de Janeiro. Especificamente, objetivamos: verificar em que posições sintáticas os advérbios temporais são licenciados; analisar a influência do fator forma do advérbio em relação ao posicionamento variável; constatar se há ou não diferenças de usos quanto à ordem dos advérbios nos dois jornais.

Pesquisar o posicionamento do advérbio a partir de situações concretas de uso possibilita-nos entender o real funcionamento desse item linguístico nas diferentes estruturas sentenciais produzidas pelos falantes. Por exemplo, um advérbio de tempo pode ser considerado como modificador? Um advérbio que ocorre no início ou meio de uma sentença tem o mesmo estatuto de um advérbio que ocorre no final? Um advérbio simples tem o mesmo comportamento de uma locução adverbial? Um advérbio no início ou no final de uma sentença sinaliza a intenção comunicativa de um falante?

Tendo como ponto de partida esses questionamentos, justificamos, então, a relevância do trabalho, pois, com ele, demonstramos peculiaridades que caracterizam o posicionamento sintático do advérbio temporal, podendo também, com esse tipo de descrição, contribuir, em particular, com a prática do ensino de sintaxe, um dos níveis de análise linguística considerado, muitas vezes, como um "bicho de sete cabeças", dada a postura metodológica assumida por aqueles que têm como suporte apenas as gramáticas de orientação normativa. 
Linha D'Água (Online), São Paulo, v. 27, n. 1, p. 139-152, jun. 2014

\section{Advérbios: Da abordagem tradicional às descrições linguísticas}

Tradicionalmente, nas gramáticas de orientação normativa, o advérbio é descrito de forma muito simplificada, fazendo-nos pressupor que se trata de um elemento linguístico com comportamento bastante homogêneo. Basicamente, é tratado como palavra invariável ${ }^{1}$ e definido como um modificador de verbo, sendo a etimologia da própria palavra um reflexo dessa propriedade: ad verbum - adjunto do verbo. Por exemplo, para Cunha e Cintra (1985, p. 529), “o advérbio é, fundamentalmente, um modificador do verbo"; para Rocha Lima (1994, p. 164), "advérbios são palavras modificadoras do verbo"; para Bechara (2009, p. 288), "o advérbio é constituído por palavra de natureza nominal ou pronominal e se refere geralmente ao verbo".

A essa propriedade básica, uma outra é acrescentada: o advérbio pode reforçar o sentido de um adjetivo e de um advérbio. Essa é a noção apresentada na maioria das gramáticas de orientação normativa, sinalizando, assim, que o advérbio tem um domínio sintático bastante restrito. No entanto, Cunha e Cintra (1985) e Bechara (2009) apontam que alguns advérbios podem ter seu domínio ampliado, em função da sua capacidade de modificar uma oração inteira. Além dessa propriedade semântica, os advérbios são classificados em diferentes classes, dadas as circunstâncias ou ideias acessórias que expressam: modo, intensidade, dúvida, afirmação, negação, lugar, tempo, ordem, exclusão, inclusão etc.

Quanto ao posicionamento nas sentenças, a descrição tradicional também é muito simplista, pois destaca o comportamento de alguns advérbios, em particular. Por exemplo, Cunha e Cintra afirmam que os modificadores de adjetivos, de particípios isolados e de advérbios colocam-se de regra antes dessas palavras; os de modo, que modificam o verbo, colocam-se normalmente em posições pós-verbais; os de tempo e de lugar podem ser colocados antes ou depois do verbo; o de negação sempre antes do verbo (1985, p. 533-534). Bechara (2009), por sua vez, defende que alguns advérbios têm certa flexibilidade de posição, principalmente aqueles que modificam a sentença inteira.

\footnotetext{
1 Segundo Neves (2000, p. 234), há casos, no entanto, que colocam em xeque o pressuposto de que o advérbio é invariável: "É que ela está meia doente, já não tem vontade"; "...não tem por lá enxada assim meia velha pra ceder para a gente?" Tratam-se de casos em que o falante flexiona o advérbio em gênero, e que, segundo a gramática normativa, se constituem em erros gramaticais. Há, também, casos em que os advérbios são empregados com sufixo diminutivo, mas que, em geral, assume o valor não de diminuição de tamanho, mas de intensificação (p.
} 234): agorinha mesmo; os castigos vinham depressinha; o povo esquece loguinho. 
Linha D'Água (Online), São Paulo, v. 27, n. 1, p. 139-152, jun. 2014

A propósito da descrição normativa, Ilari (2007) afirma que os critérios adotados por ela são claros e não contraditórios para apenas um pequeno número de casos. E acrescenta:

$\mathrm{Na}$ prática, o gramático defronta-se com inúmeros exemplos em que eles levam a classificações conflitantes; e às dificuldades de aplicação dos próprios critérios a gramática tradicional tem acrescentado as de um tratamento até certo ponto inconsequente, pelo hábito de enquadrar entre os advérbios uma quantidade enorme de palavras que apenas em algumas ocorrências particulares e em alguns ambientes sintáticos, atendem àqueles critérios. Tratar do 'advérbio' é, antes de mais nada, tomar consciência desses equívocos, constatando a diversidade de emprego dessas expressões (ILARI, 2007, p. 152).

Segundo esse autor, numa análise mais apurada do comportamento do advérbio, o primeiro critério a ser revisto diz respeito ao tipo de constituinte com o qual o advérbio estabelece o seu domínio; o segundo envolve as funções que os advérbios desempenham: "essas funções são bastante diferenciadas, o que tende a ser escamoteado quando se reconhece uma única função extremamente genérica de "modificação"' (ILARI, 2007, p. 154). Seguindo essa linha de pensamento, Costa e Costa (2001, p. 33-34) também destacam algumas das propriedades dos advérbios:

Os advérbios não formam uma classe semântica homogénea, existindo diferentes tipos de classes semânticas de adverbiais (...) Os advérbios podem ser polissêmicos, pertencendo a mais que uma classe semântica consoante o seu significado (...) Os advérbios pertencentes a uma mesma classe semântica podem exibir comportamentos sintáticos diferentes (...)

Pelas palavras tanto de Ilari quanto de Costa e Costa, percebemos a necessidade de se considerar o advérbio como um elemento de comportamento diversificado, tanto em termos sintáticos quanto semânticos. A propósito, isso já vem sendo destacado nos trabalhos de natureza linguística desenvolvidos no âmbito do português brasileiro, inclusive, nas chamadas gramáticas descritivas.

Por exemplo, Neves (2000) aponta a importância de se levar em conta os diferentes domínios de um advérbio, e não apenas aqueles tipicamente tradicionais. Segundo ela, "de um ponto de vista sintático ou relacional, o advérbio é uma palavra periférica, isto é, ele funciona como satélite de um núcleo (...)” podendo atuar "nas diversas camadas do enunciado" (NEVES, 2000, p. 234). E, para demonstrar 
Linha D'Água (Online), São Paulo, v. 27, n. 1, p. 139-152, jun. 2014

essa propriedade, a autora apresenta vários exemplos, dos quais destacamos alguns em (2) (cf. p. 234-235):

(2) a. Lembrava-se claramente.

b. Seus sentimentos são muito delicados.

c. Agonia era uma coisa muito sem graça.

d. Não passa tão $c e d o$, não (...).

e. Novamente no táxi, ele me chama a atenção (....).

f. O destino do Hospital do ex-IAPI também mudou, só que para pior para a contrariedade de seus quase 1.500 habitantes.

g. Não diz bobagem. Greve agora não vai nada bem.

h. E quem sabe se de tudo que pudesse fazer, se entre todas as reações possíveis, não era justamente isto - ceder, pagar.

i. Alguns inquéritos solicitados pelo Saps à polícia arrastam-se morosamente sem chegar à apuração policial dos crimes, muito embora as autoridades da mais alta hierarquia se empenham nisso.

Como se pode ver, além de o advérbio incidir sobre um verbo (2a), um adjetivo (2b) ou sintagma com valor adjetivo (2c), um advérbio (2d) ou sintagma com valor adverbial (2e), pode incidir também sobre um numeral (2f), um substantivo ( $2 \mathrm{~g}$ ), um pronome (2h) e a conjunção embora (2i). Segundo a autora, nesses casos, o advérbio atua de forma periférica no sintagma, incidindo sobre um núcleo (um constituinte) em particular. Mas além dessa situação, há também aquelas em que o advérbio pode incidir sobre unidades maiores, a própria oração, como em (3) (cf. p. 235):

(3) a. Provavelmente você não gostará da resposta.

b. Realmente, sentia fome. 
Linha D'Água (Online), São Paulo, v. 27, n. 1, p. 139-152, jun. 2014

Esse tipo de advérbio, em particular, faz parte de uma classe que não está prevista nas descrições normativas: advérbios modalizadores, que modalizam o conteúdo de uma asserção. Ilari (2007) aborda a respeito desse tipo de advérbio, apresentando, para tanto, os seguintes exemplos (cf. p. 155-156):

(4) a. Realmente, deve ser maravilhoso ter uma família grande.

b. Há pessoas que dificilmente perdem a calma, perdem o controle.

c. Diariamente (...) eles chegam atrasados.

d. Humanamente, é impossível fazer tanto processo ao mesmo tempo.

Denominados de advérbios sentenciais, esses itens não modificam um constituinte em particular, mas a sentença inteira. Em (4a) e (4b), os advérbios expressam a opinião/expectativa do falante em relação ao que está sendo afirmado: deve ser maravilhoso ter família grande; há pessoas que perdem a calma, perdem o controle. Em (4c), "diariamente" indica a frequência com que reitera o evento; em (4d), "humanamente" limita o ponto de vista do qual pode ser considerada correta a afirmação: é do ponto de vista humano e não de qualquer outro.

Perini (2010), em sua gramática do português brasileiro, também descreve algumas propriedades comportamentais dos advérbios, mostrando que a ordenação de um elemento adverbial depende da função que ele exerce numa sentença, se complemento ou adjunto; da relação sintática que pode estabelecer com um verbo ou nominal; e também do seu escopo (p. 318). Castilho (2010), por sua vez, aborda a respeito do estatuto categorial do advérbio, destacando a necessidade de descrevê-los considerando três campos essenciais: o semântico, o sintático e o discursivo.

Das descrições apresentadas, temos a indicação de que os advérbios formam uma classe bastante heterogênea. Como exemplo, temos os advérbios de tempo, os quais, na visão de Neves (1999), não funcionam como modificadores, pois "não operam sobre o valor de verdade da oração" (p. 239). Segundo ela, a relação estabelecida entre o advérbio e as palavras com as quais formam unidade sintática não é de modificação, como se pressupõe tradicionalmente: "De fato, se o advérbio se define como 'modificador' do verbo (ou, ainda, do adjetivo e do advérbio) (...), os circunstanciais não pertencem à classe, já que nenhum advérbio de tempo ou de lugar realmente modifica o expresso no verbo" (p. 263). São advérbios que têm seu comportamento justificado em face dos usos e das intenções comunicativas dos falantes, como veremos na próxima seção. 
Linha D'Água (Online), São Paulo, v. 27, n. 1, p. 139-152, jun. 2014

\section{Advérbios de tempo no gênero "notícia": Descrição e análise dos dados}

Para pesquisar os aspectos morfossintáticos que envolvem os advérbios de tempo, escolhemos notícias comuns veiculadas nos jornais $A$ Tarde, da Bahia, e $O$ Globo, do Rio de Janeiro. A escolha pelo gênero notícia se deu em função da prática de o falante recorrer a advérbios temporais para especificar, no momento da enunciação (momento em que o autor da notícia a divulga), o tempo em que ocorre um determinado fato. $\mathrm{O}$ interesse por pesquisá-los surgiu por conta de ainda não haver muitas pesquisas sobre o comportamento funcional desse tipo de advérbio, em se tratando de jornais veiculados em regiões diferentes do Brasil. Acreditamos que, dadas as especificidades de cada um dos jornais escolhidos, como, por exemplo, o alcance e o tipo de leitor, haverá diferenças significativas em relação aos usos dos advérbios temporais, mesmo sendo notícias que tratam dos mesmos acontecimentos.

Assim, selecionamos as notícias comuns que eram divulgadas nesses periódicos, num período de dois meses, quando reunimos um total de 28 notícias (14 de cada jornal), de onde foram coletadas 138 ocorrências de advérbios temporais, especificamente os não-oracionais, constituídos por formas simples (uma só palavra) e composta (duas ou mais palavras, denominada tradicionalmente de locução adverbial), que dispunham de maior liberdade na sentença. Usamos o critério da mobilidade (cf. COSTA; COSTA, 2001) para recortar os casos que seriam analisados. A fim de ilustrar esse teste, demonstramos, a seguir, casos em que os advérbios ocorrem na posição inicial (5), medial (6) e final (7) das sentenças. As variações apresentadas por a' e a" indicam a flexibilidade de posicionamento desse advérbio:

(5) a. Ontem, mergulhadores encontraram mais cinco corpos de quatro homens e uma mulher... (JORNAL A TARDE, 18.01.2012).

a.' Mergulhadores encontraram ontem mais cinco corpos de quatro homens e uma mulher...

a." Mergulhadores encontraram mais cinco corpos de quatro homens e uma mulher ontem...

(6) a....os EUA vão, até o fim deste ano, reduzir o tempo de espera para a obtenção do visto... (JORNAL O GLOBO, 20.01.2012).

a.'Até o fim deste ano, os EUA vão reduzir o tempo de espera para a obtenção do visto... 
Linha D'Água (Online), São Paulo, v. 27, n. 1, p. 139-152, jun. 2014

a." Os EUA vão reduzir o tempo de espera para a obtenção do visto até o fim deste ano.

(7) a. O conselho apreciará a indicação em reunião no próximo dia 9. (JORNAL A TARDE, 24.01.2012).

a.' No próximo dia 9, o conselho apreciará a indicação em reunião.

a.” O conselho apreciará, no próximo dia 9, a indicação em reunião.

Além do critério da mobilidade, usamos, também, a pergunta "quando?", cuja resposta permite a localização temporal do evento (cf. NEVES, 2000):

(8) a. Quando os mergulhadores encontraram mais cinco corpos de quatro homens e uma mulher? Ontem.

a.' Quando os EUA vão reduzir o tempo de espera para a obtenção do visto? Até o fim deste ano.

a." Quando o conselho apreciará a indicação em reunião? No próximo dia 9.

Seguindo esses critérios, estabelecemos, então, a nossa variável de pesquisa: posição do advérbio na sentença ${ }^{2}$ : início $(\mathrm{I})$, meio $(\mathrm{M})$ e fim $(\mathrm{F})^{3}$, como ilustram respectivamente os exemplos em (9), (10) e (11):

(9) Pela manhã, [a Petrobrás informou] que o presidente do conselho de administração da companhia e ministro da fazenda... (JORNAL A TARDE, 20.01.2012).

(10) ...[a Petrobrás é hoje uma empresa capitalizada]. (JORNAL A TARDE, 14.02.2012).

2 Em todos os exemplos, delimitamos, por meio de colchetes, o domínio sentencial considerado, ou seja, o domínio em que atua o advérbio.

3 Esclarecemos: posição inicial - aquela antes do sujeito; meio da sentença - antes ou depois do verbo, podendo o advérbio estar imediatamente ao lado do mesmo, ou não (com algum elemento interveniente entre eles). Final da sentença, o último constituinte sentencial. 
Linha D'Água (Online), São Paulo, v. 27, n. 1, p. 139-152, jun. 2014

(11) [Shettino foi ouvido judicialmente durante três horas]. (JORNAL A TARDE, 18.01.2012).

A análise dessa variável nos permitiu visualizar se há diferenças em relação aos posicionamentos dos advérbios nos dois jornais investigados, e, com isso, inferir sobre as intenções comunicativas dos autores das notícias. Por exemplo, se compreendem o advérbio temporal como um elemento de liberdade sintática, que pode ser licenciado em diversas posições de uma sentença; se dão relevância, primeiro, à localização temporal ou ao fato ocorrido; se o advérbio temporal é um elemento periférico ou não-periférico. Assim, para o posicionamento dos advérbios temporais, as nossas hipóteses foram:

» O posicionamento desse tipo de advérbio na sentença é variável, tendo em vista que se trata de um elemento sintático não modificador de uma categoria específica;

» Eles devem ocorrer, preferencialmente, nas posições periféricas, às margens das sentenças, inicial e final, uma vez que são tipicamente elementos circunstanciais, e não modificadores;

» Das posições periféricas, a final deverá ser a mais recorrente, pois o pressuposto é que os autores darão ênfase, primeiro, ao fato ocorrido;

" No que se refere a essas preferências, os dois jornais apresentarão diferenças, uma vez que ambos têm públicos e alcances distintos, logo, com características particulares quanto à colocação dos advérbios nas sentenças.

Quanto ao posicionamento, vejamos, então, o cômputo geral nas tabelas (I) e (II) que se seguem:

Tabela 1: Cômputo geral dos advérbios temporais em função da posição no Jornal $A$ Tarde

\begin{tabular}{ccccccc}
\hline & I & \multicolumn{2}{c}{$M$} & \multicolumn{2}{c}{$F$} \\
\hline OC & $\%$ & OC & $\%$ & OC & $\%$ \\
\hline 21 & 37,5 & 18 & 32,1 & 17 & 30,4 \\
\hline
\end{tabular}


Linha D'Água (Online), São Paulo, v. 27, n. 1, p. 139-152, jun. 2014

Como se pode perceber, no Jornal $A$ Tarde, os advérbios de tempo se posicionam variavelmente nas três posições, confirmando a nossa expectativa e corroborando as constatações de Martelotta (1994): uma das características básicas desse tipo de advérbio é o posicionamento variável. Essa mesma variação também se observa no Jornal O Globo, como se pode notar na tabela 2:

Tabela 2: Cômputo geral dos advérbios temporais em função da posição no Jornal $O$ Globo

\begin{tabular}{ccccccc}
\hline & \multicolumn{1}{c}{ I } & \multicolumn{2}{c}{ M } \\
\hline OC & $\%$ & OC & $\%$ & OC & $\%$ \\
\hline 22 & 26,9 & 17 & 20,7 & 43 & 52,4 \\
\hline
\end{tabular}

No entanto, as duas tabelas revelam resultados distintos quanto à frequência dos advérbios nas três posições. No Jornal $A$ Tarde, a preferência é pela posição periférica inicial $(37,5 \%)$, enquanto que em $O$ Globo é pela periférica final $(52,4 \%)$. Esses resultados confirmam as nossas expectativas de que o advérbio temporal seria licenciado preferencialmente em posições periféricas e que haveria diferenças entre os dois jornais quanto a essas escolhas. Quanto à posição medial, também observamos diferenças acentuadas entre os dois jornais: em $A$ Tarde, o advérbio foi licenciado mais nessa posição (32,1\%) do que em O Globo (20,7\%).

Portanto, esses resultados nos permitem inferir que os autores das notícias tiveram intenções diferenciadas quando usaram os advérbios temporais. Por serem mais frequentes nas posições iniciais, no Jornal A Tarde, os advérbios sinalizam que os autores das notícias deram ênfase à localização temporal do fato ocorrido; já, em O Globo, pelo fato de os advérbios serem mais frequentes nas posições finais, a preocupação primeira dos autores foi com a apresentação do fato.

Essas diferenças entre os dois jornais podem ser explicadas pelo subprincípio de ordenação linear, o qual prediz que a ordem dos elementos numa determinada estrutura sintática corresponde a sua ordem de importância para o falante (COSTA NUNES, 2009, p. 29). Ou seja, para os autores das notícias do Jornal $A$ Tarde, colocar o advérbio preferencialmente logo no início da sentença significa dizer que eles atribuíram mais relevância à circunstância temporal, diferentemente dos autores das notícias do jornal $O$ Globo.

Identificadas as posições dos advérbios, procuramos verificar se elas eram influenciadas pelo fator forma do advérbio (simples - uma só palavra- e não-simples - mais de uma palavra), como ilustram os exemplos abaixo: 
Linha D'Água (Online), São Paulo, v. 27, n. 1, p. 139-152, jun. 2014

" Advérbio simples no inicio da frase:

(12) Ontem, [circulavam rumores sobre a dança das cadeiras na sede da empresa...] (JORNAL O GLOBO, 24.01.2012).

" Advérbio simples no meio da frase:

(13) a. [O tribunal de justiça de Gosseto ordenou, ontem, a prisão domiciliar de Francesco]. (JORNAL A TARDE, 18.01.2012).

" Advérbio simples no fim da frase:

(14) a ... [cerca de 400 pessoas se aglomeraram na frente do Fórum de Santo André (SP) ontem]... (JORNAL A TARDE, 14.02.2012).

" Advérbio não-simples no início da frase:

(15) a. [Em março do ano seguinte, o governo anuncia o PIB oficial do ano anterior]. (JORNAL O GLOBO, 17.01.2012).

" Advérbio não-simples no meio da frase:

(16) a. [Eurozona finalmente aprovou, ontem de madrugada, um novo plano de resgate para a Grécia]... (JORNAL A TARDE, 22.02.2012).

"Advérbio não-simples no fim da frase:

(17) a. [O programa econômico foi adotado por maioria dos votos pouco antes das 23h]... (JORNAL A TARDE, 13.02.2012).

Para esse fator, hipotetizamos: por um lado, a posição final deverá ser favorecida pela forma composta, pois acreditamos que, se colocado no início da sentença, poderá interferir na apresentação objetiva do fato. Com isso, esperamos que os advérbios em sua forma simples sejam mais recorrentes no início e no meio da sentença. Vejamos, então, os resultados nas tabelas 3 e 4 : 
Linha D'Água (Online), São Paulo, v. 27, n. 1, p. 139-152, jun. 2014

Tabela 3: Posição dos advérbios temporais em função de sua forma no Jornal $A$ Tarde

\begin{tabular}{|c|c|c|c|c|c|c|c|c|c|c|c|}
\hline \multicolumn{4}{|c|}{ I } & \multicolumn{4}{|c|}{$M$} & \multicolumn{4}{|c|}{$\mathbf{F}$} \\
\hline \multicolumn{2}{|c|}{ S } & \multicolumn{2}{|c|}{ C } & \multicolumn{2}{|c|}{ S } & \multicolumn{2}{|c|}{ C } & \multicolumn{2}{|c|}{$\mathrm{S}$} & \multicolumn{2}{|c|}{ C } \\
\hline $\mathrm{OC}$ & $\%$ & $\mathrm{OC}$ & $\%$ & $\mathrm{OC}$ & $\%$ & OC & $\%$ & OC & $\%$ & OC & $\%$ \\
\hline 04 & 19 & 81 & 20,7 & 81 & 20,7 & 81 & 20,7 & 81 & 20,7 & 43 & 52,4 \\
\hline
\end{tabular}

Constatamos que, no jornal $A$ Tarde, as posições inicial e final foram influenciadas pela forma composta: $81 \%$ e $88,2 \%$ respectivamente, confirmando, em parte, a hipótese levantada: os advérbios formados com mais elementos informacionais ocorreriam no final da sentença. Para a posição inicial, o previsto seria que o advérbio fosse representado mais por estruturas simples. Isso ocorreu, apenas, com a posição medial (83,3\%). Comportamento semelhante também se observou no Jornal O Globo:

Tabela 4: Posição dos advérbios temporais em função de sua forma no Jornal O Globo

\begin{tabular}{ccccccccccccccc}
\hline & & \multicolumn{1}{c}{ I } & \multicolumn{9}{c}{ M } & \multicolumn{3}{c}{ F } \\
\hline \multicolumn{2}{c}{ S } & \multicolumn{2}{c}{ C } & \multicolumn{2}{c}{ S } & \multicolumn{2}{c}{ C } & \multicolumn{2}{c}{ S } & \multicolumn{2}{c}{ C } \\
\hline OC & $\%$ & OC & $\%$ & OC & $\%$ & OC & $\%$ & OC & $\%$ & OC & $\%$ \\
\hline 06 & 27,2 & 16 & 72,8 & 11 & 64,7 & 06 & 35,3 & 06 & 15,8 & 32 & 84,2 \\
\hline
\end{tabular}

Ou seja, a forma composta influenciou os posicionamentos inicial $(72,8 \%)$ e final (84,2\%), e a forma simples, o posicionamento medial (64,7\%). No entanto, comparando os números referentes às posições inicial e medial, observamos uma pequena diferença entre os dois jornais, o que reflete intenções diferentes por parte dos autores. No Jornal $O$ Globo, verificamos um maior uso de forma simples no início da sentença $(27,2 \%)$ do que em $A$ Tarde (19\%). Por outro lado, neste último jornal, a posição medial foi mais influenciada pela forma simples $(83,3)$ do que em O Globo (64,7\%).

Esses resultados indicam que os autores das notícias, quando localizam temporalmente o fato com formas que apresentam maior quantidade de informação, recorrem, consequentemente, a estruturas mais complexas. Isso está de acordo com o subprincipio da quantidade (cf. CUNHA, 2008): quanto maior a quantidade de 
Linha D'Água (Online), São Paulo, v. 27, n. 1, p. 139-152, jun. 2014

informação, maior a quantidade da forma. Por serem maiores, o autor prefere colocar as formas compostas em posições periféricas, de tal modo que não interfiram na apresentação objetiva do fato. As estruturas menos complexas, no interior da sentença, revelam que elas interferem menos na apresentação do fato. Conforme Cunha (2008, p. 168), “a estrutura de uma construção gramatical indica a estrutura do conceito que ela expressa”. Significa dizer que a complexidade do pensamento tende a refletir-se na complexidade daquilo que o falante expressa; ou seja, o que é mais simples e previsível é representado por itens linguísticos menos complexos, enquanto aquilo que é pouco previsível é representado por itens mais complexos.

Da análise empreendida, podemos afirmar, portanto, que a ordenação dos advérbios temporais, nas sentenças, não ocorre de forma aleatória. Dadas as intenções comunicativas dos falantes, os advérbios são alocados em diferentes lugares, podendo esse posicionamento ser também influenciado pela sua forma. Com essa constatação, esperamos suscitar novas reflexões sobre o uso e, particularmente, o ensino de advérbios temporais.

\section{Considerações finais}

Como vimos, o trabalho teve como objetivo investigar a ordenação dos circunstanciais temporais em notícias veiculadas em jornais de duas diferentes regiões brasileiras, a fim de verificar se havia diferença entre eles no que se refere aos seus posicionamentos nas sentenças. De fato, o posicionamento desse tipo de advérbio é variável, confirmando que a mobilidade sintática é uma de suas características básicas. Também, verificamos que, em sua maioria, são empregados na posição final e representados pelas formas não-simples.

Em relação à diferença de usos dos itens temporais, observamos que o Jornal $A$ Tarde revelou uma preferência pela posição inicial, e o Jornal $O$ Globo, pela final. Com essas preferências, podemos inferir: a intenção primeira do Jornal $A$ Tarde foi situar temporalmente a notícia, diferentemente do jornal $O$ Globo, que teve a preocupação primeira de apresentar o fato, e, depois, o tempo em que ele ocorreu. Essa constatação nos permite afirmar, portanto, que os usos diferenciados dos advérbios refletem diretamente as intenções comunicativas dos autores.

\section{Referências}

ANDRADE, Queli Cristina P. de. Ordenação das locuçôes adverbiais de tempo. Dissertação. (Mestrado em Linguística). Universidade Federal do Rio de Janeiro, Rio de Janeiro, 2004.

BECHARA, Evanildo. Moderna gramática portuguesa. 37. ed. Rio de Janeiro: Lucerna, 2009.

KANTHACK, G. S.; MACIEL, V. P. S. 0 uso de advérbios temporais em notíicias jornalísticas... 
Linha D'Água (Online), São Paulo, v. 27, n. 1, p. 139-152, jun. 2014

CASTILHO, Ataliba Teixeira de. Gramática do português brasileiro. São Paulo: Contexto, 2010.

COSTA, Ana; COSTA, João. O que é um advérbio? Lisboa: Colibri, 2001.

COSTA NUNES, Júlia Oliveira. A Ordenação dos Advérbios Temporais elou Aspectuais em -mente no Português escrito contemporâneo. 2009. (Mestrado em Linguística). Universidade Federal do Rio de Janeiro, Rio de Janeiro, 2009.

CUNHA, Celso. CINTRA, Lindley. Nova gramática do português contemporâneo. Rio de Janeiro: Nova Fronteira, 1985.

CUNHA, Angélica Furtado da. Funcionalismo. In: MARTELOTTA, Mário Eduardo (Org.). Manual de Linguística. São Paulo: Contexto, 2008, p. 157-173.

ILARI, Rodolfo (et al.). Considerações sobre a posição dos advérbios. In: CASTILHO, Ataliba Teixeira de. (Org.). Gramática do português falado: a ordem. V.1. Campinas: EDUNICAMP, 1990, p. 63-141.

ILARI, Rodolfo. A categoria advérbio na gramática do português falado. In: Revista Alfa. São Paulo, 51 (1), 2007, p. 151-174.

MACIEL, Viviane Purcina de Santana. Advérbios temporais: descrição e análise do comportamento sintático e semântico nos Jornais a Tarde, da Babia, e o Globo, do Rio de Janeiro. (Dissertação de mestrado). Universidade Estadual de Santa Cruz, Ilhéus, Bahia, 2014.

MARTELOTTA, Mário Eduardo. Os circunstanciadores temporais e sua ordenação: Uma visão funcional. 1994. (Tese de doutorado). Universidade Federal do Rio de Janeiro, Rio de Janeiro, 1994.

NEVES, Maria Helena de Moura. A gramática funcional. São Paulo: Martins Fontes, 1997.

. Os advérbios circunstanciais (de lugar e de tempo). In: ILARI, Rodolfo. (Org.). Gramática do português falado: níveis de análise linguística. São Paulo: Unicamp, 1999, p. 263-296.

. Gramática de usos do português. São Paulo: UNESP, 2000.

PERINI, Mário Alberto. Gramática do português brasileiro. São Paulo: Parábola Editorial, 2010.

ROCHA LIMA, Carlos Henrique. Gramática normativa da lingua portuguesa. 32 (ed. retocada e enriquecida). Rio de Janeiro: José Olympio, 1994.

Recebido em 31/03/2014

Aprovado em 21/05/2014

KANTHACK, G. S.; MACIEL, V. P. S. 0 uso de advérbios temporais em notícias jornalísticas... 